\title{
La saviesa, una mica més òrfena Plany a Josep M. Pujol (1947-2012)
}

qu'om li traga lo cor e que•n manio'l baro que vivon descorat, pueys auran de cor pro. SORDEL (BdT 437, 24)

Amb cor trist i marrit, des de Mot so razo volem adreçar uns lleugers mots, sense metre i mal girbats, en memòria de Josep M. Pujol i Sanmartín. La seva mort prematura fa poc més d'un any, el passat 26 d'agost de 2012, ha deixat una buidor a tots aquells que l'hem tingut com a mestre, company o amic que no pot palliar el record, ni la gratitud, ni tampoc el seu llegat.

Després d'haver treballat en el món editorial, d'on li va néixer la passió per la tipografia, empesa pel poeta Gabriel Ferrater, es va dedicar a la recerca i a la docència. Des de 1979 era professor del Departament de Filologia Catalana a la Universitat Rovira i Virgili de Tarragona (abans Universitat de Barcelona), on impartia assignatures de Literatura romànica, Literatura catalana medieval, Edició de textos, Etnopoètica i Folklore narratiu. També era professor d'història de la tipografia al Centre Universitari de Disseny i Art EINA de Barcelona i va collaborar en diversos cursos de màster i postgrau per a editors i dissenyadors gràfics.

Era un expert de primer ordre en totes aquestes disciplines, que ell podia capir i sentir en la totalitat. Això li permeté fressar per camins inescrutables fins aleshores - abans que estigués en voga la interdisciplinarietat- amb resultats sorprenents, originals, fructífers i sòlids. No és en va que les seves obres hagin esdevingut de referència, fites que marquen el bon camí. Pensem en l'indispensable Manual d'ortotipografia, juntament amb el seu bon amic, també malaguanyat, Joan Solà (Columna, 1995), la introducció «Jan Tschichold y la tipografía moderna» a la traducció castellana de Tschichold (La nueva tipografía,
Campgràfic, 2003), Benvingut/da al club de la SIDA i altres rumors d'actualitat, amb el Grup de Recerca Folklòrica d'Osona (2002), o l'Index of Catalan Folktales, amb Carme Oriol (2008).

$\mathrm{Ha}$ bastit els fonaments per a l'estudi de la tipografia a la península i per a l'estudi del folklore a casa nostra, que ha enaltit a una disciplina moderna i l'ha situada en l'àmbit internacional, com ha fet amb la cuina catalana Ferran Adrià. De fet, els seus articles són d'expressió exquisida, on es cou la més vasta erudició i l'entranyable saviesa popular, sempre amanit amb un pessic d'ironia ben fina.

També hi ha un abans i un després en la interpretació del Llibre dels fets del rei Jaume I, i s'hauria afinat més en la lectura i en la fixació del text si la malaltia no hagués interromput l'edició crítica que estava cuinant des de feia anys, com molt bé ens recorda en Xavier Renedo, excellent company i continuador de la via encetada per Josep M. Pujol i Stefano Asperti, en el deliciós article que ret al mestre Pujol en aquest mateix número de MSR, al qual remeto. La recerca en l'àmbit de la romanística no només va abastar el Llibre dels fets: en ment li coïen hipòtesis sobre els trobadors o la narrativa en vers, per exemple, que insinuava a les seves classes magistrals, però que no s'han arribat a materialitzar mai amb els soldadets de la host de Gutenberg. Tampoc en queden rastres als apunts esparsos, de quatre frases avui inconnexes —com bé apuntava Antoni Veciana al seu bloc- - ja que tant si entonava discretament càntics encara amb veu melodiosa, com si durant hores ens descobria els misteris del punt volat, la impetuositat fatxenda de Rotllà, l'humor jocós, sagaç i autocomplaent del rei En Jaume el Recontador, o com es regentava una coma al poble de Vetusta, ens quedàvem tan 
embadalits escoltant-lo, que ens deixàvem endur per l'oblit que mou el jòi.

El seu perfeccionisme i el respecte escrupolós al procés de maduració intellectual a vegades li impediren de publicar algunes obres sempiternes, que ell mateix s'autoeditava en forma d'opuscles en quartilla. Sempre sollícit, la seva liberalitat li'n feia fer còpies que divulgava d'estranquis entre el cenacle dels millors especialistes o curiosos, delerosos del seu parer. En són exemples la gramàtica d'occità antic «Esquemes pràctics de morfologia de la llengua occitana medieval» o el seu manual «Recomanacions per a l'edició de textos catalans medievals». És potser a l'ombra de l'inèdit on més ha poat la seva influència.

No ens volem entretenir amb el seu currículum acadèmic, perquè ens fa l'efecte que en lloc d'enaltir la seva figura, l'allunya i la pixella. Josep M. Pujol era un savi, en totes les accepcions del terme. Aquell a qui tothom recorria quan es trobava un escull infranquejable, aquell que sempre tenia la resposta justa i oportuna per a cadascú i en cada cas. En ell es trobaven reunides amb mestria la ciència i la sapiència, l'elegància i la calidesa, la largueza i la cortesia.

\section{La lletra està de dol}

Agraïm als dissenyadors Diego Feijóo, Sabina Monza-Goday, Josep Babiloni i Dani Rubio Arauna la cessió de les seves obres, que illustren amb simplicitat i gentilesa el plor silent de la lletra per la mort del mestre. Ens sumem, així, al seu «clam de mercès»».

Els dissenys formaven part de l'exposició «Homenatge a Josep M. Pujol» que l'escola EINA li va retre del 16 d'abril al 4 de maig de 2013 a l'Espai Barra de Ferro.

Marina NavÀs, Universitat Rovira i Virgili

\section{ABCDE FGHI KL N O QRS TUVW XYZ}

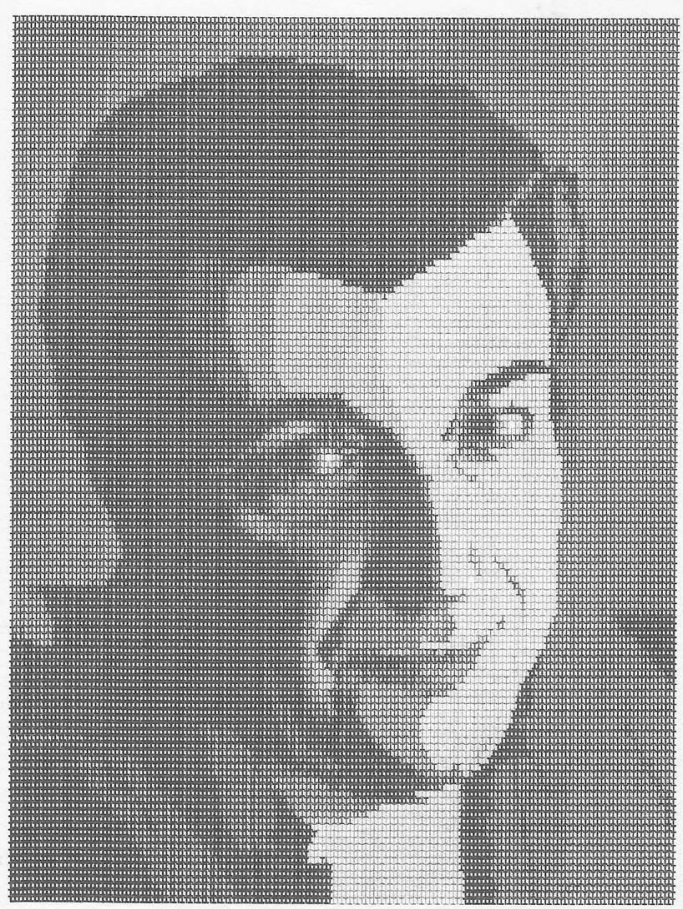

Josep Babiloni 


\section{tipogiafia}




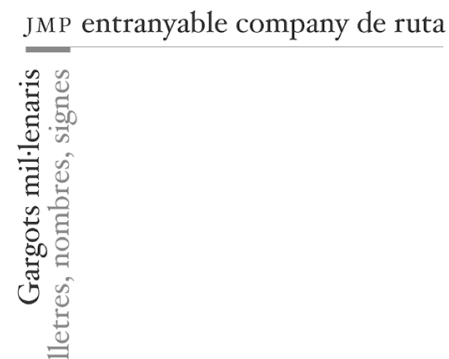

